\title{
Case Grammar and its Application in English Vocabulary Teaching
}

\author{
Bei-bei Ye \\ School of Foreign Studies, Yangtze University, Jinzhou, Hubei Province, China
}

\begin{abstract}
In 1968, Fillmore published his theory of Case Grammar, which highlighted the fact that syntactic structure can be predicted by semantic participants. It focuses on the link between the number of subjects, objects and so on of a verb and the grammatical context it requires. Fillmore's case theory is not produced to be applied in foreign language teaching at the beginning. However, people have realized that some research findings of case grammar can indeed be applied in foreign language teaching, vocabulary teaching is in the case. This article will briefly introduce what case grammar is and its application in vocabulary teaching.

Index Terms - Case grammar, English vocabulary teaching, application
\end{abstract}

\section{How did Case Grammar Come into Being?}

In Latin, the role of words in a sentence or the word relationship with others is reflected by the change of suffix forms. These specific suffix forms were given a specific meaning. We call this particular mode as case of a word. Generally, there are six cases in Latin, described as nominative, accusative, genitive, dative, ablative and vocative. Nominative is usually the subject of the sentence, for instance, English pronouns She, I, You etc. Accusative is the acceptor of the action, usually the case of direct object, for instance, me, him she in English. Genitive is case of the attribute, such as my, her in English. Dative is the case of indirect object. In English, it is modified by prepositions such as to, for and so on. Ablative is used to express instrumental, method, concomitant. In English, it is modified by prepositions such as by, with, in, from etc. Vocative is used to name a person, an animal or an object.

All the above cases are connected with syntax, and so they are called syntactic case. The case is varied as the position of the word is changed in the sentence. They are actually transformational-generative grammar. Fillmore pointed out that these cases attached great importance to grammar while ignoring semantics. As a result, he came up with the idea of case grammar.

\section{What is Case Grammar?}

In 1968, Fillmore published his theory of Case Grammar (Fillmore 1968), which highlighted the fact that syntactic structure can be predicted by semantic participants. It focuses on the link between the number of subjects, objects and so on of a verb and the grammatical context it requires. The underlying structure of the syntactic and semantic relationships between nouns and verbs related with it is deep case. This kind of case doesn't have to be shown through the change of the morphology of nouns and pronouns. The case is determined based on the underlying structure of the syntactic and semantic relationships between nouns and verbs. Once these relationships have been determined, they are fixed; no matter what position they are in the surface structure, what grammatical relations they are with verbs. The case in the deep structure has no correspondence relationships with any particular language and grammar concepts in the surface structure, such as subject, object, etc. As for the case of case grammar, Fillmore called the issuer of the action agentive case; the affected substance of the action objective case; the object caused the action instrumental case; the result of the action factitive case and so on. Here is an example to have a better understanding of case grammar:

The door opened.

门开了。

The key opened the door.

钥匙开了门。

The boy opened the door.

男孩开了门。

The door was opened by the boy.

门被男孩打开了。

The boy opened the door with a key.

男孩用钥匙开了门。

"The door" in the first sentence is the subject. But to our knowledge, the door can't open itself. It's opened by the people. So according to case grammar, "the door" is the affected substance of the action. We may call it the objective case. The same goes to "the key" in the second sentence. "The key" in the second sentence is the subject. However, the key can't open the door by itself. It is the people who use the key to open the door. So the key is an instrument with which people can carry out an action. Here, we call the key instrumental case on the basis of case grammar. "The boy", obviously, it is the issuer of the action. Without any doubt, it is the agentive case. The fourth and fifth sentences can let people have a clear understanding of the relationship between the verbs "open" and the rest nouns "the door", "the key" and "the door". That is to say, no matter what the three nouns are in grammar structure or no matter whether the sentence is active voice or passive voice, from the angle of semantics, "the boy" is always the issuer of the action "open"; "the door" is always the object of the action "open"; "the key" is always the instrumental of action "open". Therefore, in the scope of case grammar, these nouns each belong to a particular kind of case.

From above, we can see that this kind of case in deep structure cannot be compared with neither subject or object in surface structure nor cases of inflectional surface structure. 
The case is determined by the semantic relations. To some extent, it has some relationships with the grammar, but the relation is not strictly correspondent. Fillmore advocated the concept of traditional case be divided into two parts: form and meaning. The morphology studies the variation of inflectional forms, such as adding "-s" or "-ed". The case grammar studies the meaning of cases, which is the syntactic - semantic relation in the deep structure of the sentences. The form of the case differs from language to language, but the case relationship is the same.

\section{The Application of Case Grammar in English Vocabulary Teaching}

After having been produced in the late 1960s, the case grammar has aroused strong repercussions in the field of language study. Even it caused a situation of tripartite confrontation along with the expandable standard theory of Chomsky's and generative semantics. Undoubtedly, it has been widely used. Mainly, people have applied the case grammar to English language teaching, English-Chinese translation, machine translation system and so on. The following will present its application in English vocabulary teaching.

When learning a foreign language, vocabulary learning is the very first step and also the basic step. Generally, the most common way for Chinese learners of English to learn vocabulary is through memorization their Chinese equivalents. As a result, they will encounter many words with the same Chinese meaning, which makes them confused and may have problems in doing exercise. Here comes the example:

1) The need for attending the party ___ great costs.
A. Produces
B. generates
C. manufactures
D. grows
2) The trees in the strong wind.
A. were shaking
B. were being shaken
C. shake
D. are being shaken

As for the first example, the students may feel puzzled about the answer which is B. According to their memorization of the Chinese equivalents, both "generate" and "grow" have the similar semantics. How about the answer D? However, same meanings as these two verbs have, regarding to case grammar, they require different mappings. The subject of the word "generate" needs to be the issuer of the action and the object of this word needs to be the object produced by this action. While the word "grow", its subject can be the object affected by the action which means increase. Therefore, in line with the requirement of the context, the answer B is what we want.

The same case goes for the second example. Under the guidance of case grammar, the verb "shake" describes a scene in which something is waggling under the action of some kind of power. There are two entities in this scene: the power of producing this action is the subject and the entity affected by the action is the object. The function of a sentence is to highlight the described entity. When we say "I shook the trees" or" The trees were shaken by me", both entities of the verb "shake" have been presented in this scene. But when we say "The trees shook", there are still two entities in this scene and the emphasized one is the one affected by the action "the trees" without showing who makes the trees shake, the people, the wind or other power. But indeed, the trees are shaking under some kind of power. So, as for the second example, B is the correct answer. There is no need to use passive voice in this sentence.

\section{Conclusion}

Undoubtedly, since having been produced in the late 1960s, the case grammar has aroused great influence in the field of language study. Even it caused a situation of confrontation along with the expandable standard theory of Chomsky's and generative semantics which is most discussed at that time. It gives people a new idea of understanding the words and sentences. What's more, it has been widely used. And its application in English teaching shows a new aspect for English teachers to solve the problems frequently appearing in students' English vocabulary learning.

\section{References}

[1] Fillmore, Charles J. The Case for Case. In Emmon Bach and Robert Harms. Universals in Linguistic Theory. New York: Holt - Rinehart Winston, 1968: 1-88.

[2] Liu Hongyu, From Case Grammar to FrameNet and to Construction Grammar. Journal of PLA Foreign Languages Institute, 2011, (1): 5-10.

[3] Li Weina, Application of Case Grammar Theory in Basic English Teaching. Journal of Guangxi Normal University, 2011, (2): 80-83. 